Doi: $10.32481 /$ djph.2021.09.008

\title{
An Interview with Lieutenant Governor Bethany Hall-Long
}

James Ellison, MD, MPH

Geriatric Psychiatrist; Swank Foundation Endowed Chair, Memory Care and Geriatrics, ChristianaCare; Editor in Chief, Journal of Geriatric Psychiatry and Neurology

James Ellison: Lieutenant Governor Hall-Long, thank you for offering to share your thoughts about the importance of dementia and the care of affected older adults in Delaware.

Lieutenant Governor Hall-Long: I'm glad to join you today. The challenge of dementia in our state is so real. Alzheimer's, and of course other dementias, are among the most important healthcare challenges facing us, we need to care for Delawareans. I call them the three A's: autism, Alzheimer's, and addictions. These are critical brain health issues.

JE: I know that not only as a legislator, but as a former health care clinician, and as a family member, you've been very concerned about the welfare of people with neurocognitive disorders such as dementia.

BHL: Dementia is one of the top health concerns for our state, as you know, as it is nationally. As we see our population age increasing, dementia is increasing and its effects on quality of life can be devastating. Delaware has been very active in studying the problem, developing a state plan, and promoting our local version of Dementia Friendly America, which is Dementia Friendly Delaware. We need to continue developing our work force in our community and in long term care - that's a major concern - and we have mapped out some of the concerns in our Behavioral Consortium report.

JE: Delaware has been a welcoming state for older adults, hasn't it?

BHL: Yes, in addition to our own aging population we are one of the top destinations for retirees, particularly along our coastline and our beaches. And we are committed to helping our older population remain vibrant and active. We want to keep our community healthy, because a healthy community enjoys a better quality of life, and also keeps our state's economy healthy.

JE: You have been active in supporting public health.

BHL: Yes, I continue as a professor in public health nursing, and I remain active clinically. During the pandemic, in my nursing faculty and Delaware Medical Reserve Corps role, I administered nearly 3,000 vaccines in the arms of Delawareans up and down the state! And I have been very committed to addressing the needs of our older adults through agencies including DSAAPD [the Division of Services for Aging and Adults with Physical Disabilities], Dementia Free Delaware, DPH [Division of Public Health], and the ongoing work of the Behavioral Health Consortium, which is a think tank of Delaware citizens and also experts in health care policies and delivery. We're really excited about Dementia Free Delaware, which grew out of the State Plan for Alzheimer's.

JE: Dementia Friendly Delaware offers some great services, like the nurse navigator program and caregiver support training through the SAVVY Caregiver classes, to help support the care of people with dementia in their homes and the outpatient care system.

BHL: Right, and looking to the future, it is our hope that the state's Bridge Clinics will be able to expand services to help address the needs of our cognitively impaired elders. Care 
coordination is so important - whether that care is coordinated through a nurse navigator, or through effective communication in our healthcare institutions - and it's important for our senior centers and state service centers to be on board, too, to create that necessary seamless connection among support services. Another way we can make Delaware more dementia friendly is to educate everyone who comes into contact with older adults with cognitive challenges. We are educating our community members, law enforcement personnel, as you know, and our faith leaders, and working to support our Senior Centers' accessibility.

JE: In addition to law enforcement, which learns about dementia through the Crisis Intervention Training programs, Delaware has sponsored dementia training for lawyers, hasn't it?

BHL: Yes, I'm delighted that Delaware's leading the way. The Bar Association really stepped up and made available training for the attorneys, who are dealing with families who are going through some very difficult times related to dementia. It's hard for families stressed by dementia to make the difficult decisions they sometimes have to make, and they sometimes need to rely on the assistance of attorneys. By educating our legal system about dementia, we help support families who need legal services, for example when a surrogate decision-maker or guardian needs to step in. This allows families to keep a person with dementia safer, and they don't feel so alone with the difficult decision-making that is sometimes necessary. It also ultimately reduces the cost to our care system that might occur if we were less proactive.

Hand in hand with this, we also want our families who are caring for people with dementia to be educated and know what resources are available. Many families aren't aware of the resources which are open to them. In Delaware we have the helpful 211 phone number, and also services through DSAAPD and the DSAMH [Division of Substance Abuse and Mental Health] Hope Line 1-833-9-HOPEDE (833-946-7333) to help people find the resources they need. And caregivers can access the SAVVY Caregiver trainings, which are available free of charge in multiple locations around the state. Caregiver support is so important because caregivers have to remember to take care of themselves, too. Otherwise, they can get run down and burned out. We really value our caregivers and we encourage them to use these resources that are available to them, most of them free of charge.

In addition, Delawareans should know about the Nursing Home Residents Quality Assurance Commission - they have access to the executive director at 302-824-2956. And there is also an incident complaint referral center that they can access at 1-877-453-0012.

JE: I know you have also been supportive of optimizing the quality of care for people with dementia in our Long-Term Care facilities.

BHL: The importance of Long-Term Care is pretty incredible! We want to support care at home so long as that is appropriate and safe, so if we can increase early detection and intervention, we can improve the quality of life for people with dementia and their caregiving families and reduce the overall burden, including cost, associated with this dementia. And even with the most caring families, residential care of people with dementia sometimes becomes necessary - so it's important to have that resource available.

Quality care of people with dementia in residential facilities requires skill and education. We have learned over the years that if clinicians and frontline workers in those settings have the training, they can do a better and safer job of providing care. That was the important principle that led to House Bill 159. We wanted to make sure physicians, nurses, and others received 
annual training around Alzheimer's disease and other dementias. We need to recruit more dementia experts to our workforce, but we can also upgrade the expertise of our current families and workers.

JE: Between home care, residential care, emergency room visits and hospital admissions, the cost of dementia care highlights the magnitude of the burden on families and our state that we can attribute to Alzheimer's Disease and the other devasting dementias.

BHL: Yes, the cost of dementia care is staggering. Recently, the American Public Health Association published a report that estimated the cost of dementia care in the US exceeds 300 billion dollars per year, much of that from Medicare and Medicaid, but also a huge cost to caregivers keeping their loved ones at home. Costs keeps rising - in 2020 it's estimated to pass 1.1 trillion dollars. Groups like Dementia Friendly Delaware, and the Behavioral Health Consortium, and advocacy groups, and our own Delaware Nursing Home Residents Quality Assurance Commission play such important roles. We need to support home care, and Delaware needs residential facilities to meet the challenges imposed by the care of people who not only have dementia, but also behavioral symptoms that complicate care. And we need outpatient clinicians with expertise in dementia care in order to support the evaluation and treatment of people with dementia in our primary care practices.

JE: You'll be excited to learn that a program which supports primary care of people with dementia, the ADC (Alzheimer's and Dementia Care) program pioneered at UCLA, is about to become available at the Smyrna and Middletown ChristianaCare primary care practices. This is a program that offers the expertise of a dementia care specialist Nurse Practitioner to support detection, care planning, treatment, and the linking of families with resources.

BHL: Oh, that's wonderful. Integrated and collaborative care models, you know, have so much to offer - they can prevent missed opportunities for improving care and supporting families. We've also seen the growth of telehealth in Delaware during the pandemic, which is another way that specialists can increase their accessibility, and also supplement primary care without requiring vulnerable or frail patients to travel to a distant specialist. Reaching families in this way is an important tool in our growing toolkit. Telehealth is particularly applicable when somebody is homebound, or it would be very difficult or disruptive or dangerous for them to try and travel.

JE: Before we end, today, are there other thoughts you'd like to share?

BHL: I think of care as including pillars that structure our interventions. Quality prevention is the first, and so important for families. Then treatment resources, which need additional support from wraparound services such as attention to social determinants, appropriate and accessible housing, and availability of transportation options. And we have to keep caregivers in mind some of them while giving care to a person with dementia, need services themselves for medical or behavioral conditions or substance use disorders. We need to think of the family unit and support system holistically and make sure the resources that are needed are available and that families know how to access them. Then, we need to strengthen our care system by building a stronger workforce in healthcare and in residential facility care. We have just lived through the tragic loss of many of our most vulnerable elders in residential care during the pandemic - an experience that really highlights the importance of considering the needs of these members of our population. 
JE: Thank you, Lieutenant Governor Hall-Long, for contributing your thoughts about dementia care in Delaware. And thank you for the important work you and your colleagues are doing to make care safer and more effective for our people with dementia and their support systems.

Copyright (c) 2021 Delaware Academy of Medicine / Delaware Public Health Association.

This is an Open Access article distributed under the terms of the Creative Commons Attribution Non-Commercial License (https://creativecommons.org/licenses/by-nc-nd/4.0/) which permits unrestricted non-commercial use, distribution, and reproduction in any medium, provided the original work is properly cited. 